\title{
RESILIÊNCIA, ORIENTAÇÃO SEXUAL E AMBIENTE DE TRABALHO: UMA CONVERSA POSSÍVEL?
}

\author{
Helio Arthur Irigaray \\ Doutor em Administração de Empresas \\ Fundação Getúlio Vargas \\ Rio de Janeiro - Rio de Janeiro - Brasil \\ helio.irigaray@fgv.br \\ Cristina Chaves Goldschmidt \\ Mestre em Gestão Empresarial \\ Fundação Getúlio Vargas \\ Rio de Janeiro - Rio de Janeiro - Brasil \\ cristinacgoldschmidt@gmail.com \\ Luiz Gustavo Mauro de Queiroz \\ Mestre em Administração \\ Fundação Getúlio Vargas \\ Rio de Janeiro - Rio de Janeiro - Brasil \\ gus1971@gmail.com
}

\section{RESUMO}

O objetivo desta pesquisa foi discutir as estratégias de sobrevivências dos homossexuais masculinos, nos ambientes de trabalho, à luz dos conceitos de resiliência e adaptabilidade. Para tal, conduzimos uma pesquisa empírica, na qual observamos o cotidiano de diversas empresas, Rio de Janeiro e São Paulo, entrevistamos individualmente alguns de seus empregados homossexuais masculinos e, também, realizamos um grupo de foco. Estes relatos, anotações e entrevistas foram transcritos e submetidos à análise do discurso. Ficou evidente que os indivíduos em questão demonstraram, por meio de suas narrativas, adotarem comportamentos convergentes com a denominada "resiliência performativa". No limite, tais profissionais buscam adotar comportamentos que os tornem conformes e aceitos perante as normas sociais vigentes; todavia, esta estratégia de sobrevivência resulta em custos psicológicos. Tais custos se traduzem nos esforços que precisam realizar para superar situações de estresse recorrentes em suas vidas, advindas de possível discriminação ou preconceito - real, iminente ou meramente percebido. Há indícios de que estes indivíduos se mantêm ajustados socialmente, bem como sejam superficialmente adaptados, mas que, em contraponto, ainda vivam em angústia ou omissão. $O$ tornar-se resiliente e adaptável nesse caso se faz com possíveis prejuízos à saúde psicológica e ao desempenho profissional desse grupo.

Palavras-chave: Adaptabilidade; Discriminação; Orientação sexual; Resiliência.

\section{RESILIENCE, SEXUAL ORIENTATION, AND WORK ENVIRONMENT: A POSSIBLE CONVERSATION?}

\begin{abstract}
The objective of this research was to discuss the survival strategies of male homosexuals in the workplace in the light of the concepts of resilience and adaptability. Thus, we conducted an empirical research, in which we observed the daily life of several companies in Rio de Janeiro and São Paulo. We interviewed some of their male homosexual employees, and also performed a focus group. These reports, notes and interviews were transcribed and submitted to discourse analysis. It was evident that the individuals demonstrated, through their narratives, behaviors convergent with the so-called "performative resilience". At the limit, these professionals seek to adopt behaviors that make them to accept the current social norms; however, this survival strategy results in psychological. These costs translate into the efforts they need to make to overcome recurrent stress in their lives, arising from possible discrimination or prejudice - real, imminent or merely perceived. There are indications that these individuals remain socially adjusted, as well as superficially adapted, but that they still live in anguish or omission. Becoming resilient and adaptable is important, with possible harm to the psychological health and the professional performance of the group.
\end{abstract}

Keywords: Resilience; Adaptability; Sexual orientation; Discrimination. 


\section{INTRODUÇÃO}

Historicamente, a sexualidade tem sido condicionada por padrões morais mais ou menos arbitrários, sustentados ou por determinações de caráter religioso ou por argumentos médicos. No caso da homossexualidade, ao longo dos séculos, ela tem sido caracterizada como crime, pecado ou patologia pelo Estado, Igreja Católica e Ciência, respectivamente (Lopes, 2002).

Ao contrário de outras minorias, que são descriminadas em função de suas características físicas ou mentais - negros, mulheres, deficientes e obesos - os homo e bissexuais o são por conta da percepção social de que sua orientação sexual é reflexo de desvio de conduta moral (Lopes, 2002), podendo refletir negativamente em seus desempenhos profissionais (Irigaray; Freitas, 2013). De fato, a história ocidental foi construída sobre o paradigma de que o amor e o erotismo entre duas pessoas do mesmo sexo são "[...]torpes, sujos, desonestos e pecaminosos, motivos da ira divina, e que resultam em castigos contra a humanidade com pestes, inundações, terremotos e pragas" (Mott, 2006, p.47).

Esta estigmatização tende a resultar para os homossexuais em pesada carga psíquica, denominada minority stress (Ragins et al., 2003), a qual no limite pode comprometer seus desempenhos profissionais (Queiroz, 2013).

A crença na superioridade da orientação heterossexual tem resultado na exclusão, proposital ou não, de indivíduos não heterossexuais de políticas públicas e organizacionais. No ambiente organizacional, o incrustamento de valores heterocêntricos resultou em práticas discriminatórias contra as lésbicas, gays, bissexuais, travestis e transgêneros (Lgbtt) no que tange a salários e benefícios (Irigaray, 2013), bem como na probabilidade de que estes sejam alvo de agressões físicas ou verbais (Gebert; Buengeler; Henitz, 2017).

Para sobreviver neste ambiente hostil, os homossexuais adotam diversas estratégias de sobrevivência. Há aqueles que explicitam sua orientação sexual em todas as arenas sociais que atuam; outros que assumem sua orientação sexual apenas na vida privada; e ainda, aqueles que escondem radicalmente sua orientação sexual em todos os espectros de sua vida social (Irigaray; Freitas, 2013). Estas diversas estratégias de sobrevivência remeteram-nos aos estudos sobre resiliência humana.

Embora o conceito de resiliência humana ainda seja influenciado por outros de elasticidade e invulnerabilidade nos estudos iniciais no campo da Psicologia; na realidade, a resiliência é um processo dinâmico cujo resultado é a adaptação positiva ou bem-sucedida e a transformação do indivíduo, ante as adversidades (Vieira; Oliveira, 2017). Como uma capacidade processual, dinâmica e ecossistêmica, a resiliência é acionada em resposta a eventos cuja qualificação como adversidade é dependente de uma apreciação que varia individualmente. A forma como essa capacidade se manifesta determinará um resultado de adaptação positiva, que pode ser saudável ou não (Goldschmidt, 2015).

A adaptação (positiva) como indicador da resiliência, ou como o resultado de um processo resiliente de enfrentamento da adversidade (Zautra et al., 2010), suscita discussões sobre os limites do indivíduo para se adaptar, a partir da noção de positivo, qualificando a adaptação que é entendida como resiliente. As discussões sobre adaptação positiva como demonstração de resiliência apontam para os limites a que a manifestação de comportamentos sociais conformes está sujeita. Assim, a resolução para adversidades que termina em uma adaptação positiva pode também não ser construtiva. Adaptar-se pode gerar resultados destrutivos para os indivíduos. (Kamlot, 2017).

Neste sentido, o propósito deste artigo é responder a seguinte pergunta de investigação: em que medida estas estratégias de sobrevivência adotadas pelos homossexuais, no ambiente de trabalho, podem ser interpretadas como reificação de resiliência em si?

Neste trabalho, entendemos reificação como qualquer processo em que uma realidade social ou subjetiva de natureza dinâmica e criativa passa a apresentar determinadas características : fixidez, automatismo, passividade -' de um objeto inorgânico, perdendo sua autonomia e autoconsciência (Lara; Oliveira, 2017). 
Este trabalho está estruturado em cinco seções, além desta introdução. Na próxima, resgatamos o marco teórico, nomeadamente as discussões sobre o constructo resiliência, bem como sobre a sexualidade no ambiente de trabalho. A terceira seção trata do percurso metodológico. Na quarta, apresentamos os resultados da pesquisa empírica, os quais são discutidos, à luz do referencial teórico, na quinta e última seção.

\section{RESILIÊNCIA: RESGATANDO O CONSTRUCTO}

Resiliência é um constructo importado da Engenharia de materiais e que tem sido sistematicamente utilizado na Administração (Lengnick-Hall, 2011).

$\mathrm{Na}$ Engenharia e na Física, resiliência está relacionada à capacidade que a zona elástica de um material tem de voltar ao normal depois de cessada a fonte de energia que causa a deformação (Brandão et al., 2011). Assim, a noção de resiliência para físicos e engenheiros está relacionada ao limite de elasticidade que um material apresente.

No campo da Administração, este conceito surge como produto da interação entre o sujeito ou o sistema e o meio em que está inserido, delineando duas perspectivas: a da resiliência das pessoas no ambiente organizacional e a das organizações. Paralelamente, a palavra resiliência tem sido cada vez mais frequentemente utilizada pelo pop-management, em matérias e entrevistas de publicações como as revistas HSM Management, Harvard Business Review, Você S.A. e Exame (Carneiro, 2015).

Neste campo, a resiliência é analisada em níveis diversos: dimensões básicas como a biológica, a cognitiva, a emocional, a comportamental, a perspectiva das fases da vida humana, a dimensão social e a organizacional/comunidade, e sob a ótica de aspectos étnicos e de diferentes dimensões culturais.

Do ponto de vista histórico, existem dois grandes discursos sobre resiliência humana - o fisiológico e o psicológico (Tusaie; Dyer, 2004). Fisiologicamente, os seres humanos dispõem de mecanismos homeostáticos para promover a resiliência em caso de adversidade, tal como hemorragias ou estresse (Jackson et al., 2007). No campo psicológico, remete ao fenômeno de as pessoas permanecerem saudáveis apesar de expostas a severas adversidades (Rutter, 2007).

\section{O QUE TEM SIDO DITO SOBRE RESILIÊNCIA?}

A resiliência psicológica é definida como a capacidade de seguir em frente de maneira positiva, mesmo estando exposto a experiências adversas, negativas ou positivas, traumáticas ou estressantes (Tugade; Fredrickson, 2004). É um conceito amplo que se refere a processos ou padrões de adaptação positiva e desenvolvimento, em um contexto de risco e adversidade (Luthar et al., 2000; Zautra et al., 2010; ONG et al., 2010).

Há duas condições críticas implícitas na noção de resiliência: exposição à adversidade (ameaça/risco ou evento positivo) e alcance de adaptação positiva. Por definição, a resiliência é posicionada de forma interdependente da adversidade, ou seja, para demonstrar resiliência, é preciso primeiro encontrar adversidade ou desafio (Zautra et al., 2010; Masten; Wright, 2010; Kent; Davis, 2010).

Embora a resiliência se apresente sob definições e caracterizações eivadas de certa variação, há dois temas dominantes que são centrais ao conceito de resiliência: (1) como uma resposta a eventos estressores/adversidades, a resiliência foca na recuperação (recovery), que é a habilidade de se recuperar do estresse, a capacidade de reaver o equilíbrio (físico e psíquico) rapidamente, retornando ao equilíbrio, ao estado saudável ou produtivo (Irigaray; Paiva; Goldschmidt, 2017 ); e (2) a resiliência, como um resultado da adaptação bem- sucedida à adversidade, implica a continuidade da trajetória de recuperação, gerando sustentabilidade (sustainability) do equilíbrio saudável que permite a melhoria das capacidades funcionais para lidar com estresse/adversidade 
futuro, e continuar seguindo em frente em face da adversidade (Bonanno, 2004), como em um ciclo virtuoso.

Apesar de a resiliência humana especificamente compreender diferenças individuais em face de experiências adversas, ela não deve ser conceitualizada como um traço ou característica estático de um indivíduo, pois é resultado de vários processos e interações que vão além do corpo humano, e incluem relacionamentos interpessoais e o contexto social para o alcance de adaptação positiva.

Ainda na abordagem da resiliência como um processo que resulta em adaptação positiva, Carver (1998) sugere uma distinção entre: a) resiliência, como um retorno ao nível de funcionamento anterior, ou seja, recuperação ou bouncing back, e b) thriving (superação), como uma movimentação para um nível superior de funcionamento após um evento estressante.

Assim, neste estudo, corroborando com Irigaray, Paiva e Goldschmidt (2017), entendemos que resiliência seja a capacidade processual, dinâmica e ecossistêmica, que é ativada por indivíduos e sistemas em face de adversidades, para a geração de uma resposta que permita a recuperação do equilíbrio e a realização de uma adaptação positiva, mediante o acionamento de elementos ou ativos nos planos subjetivo ou interno e objetivo ou externo, que poderão ser reforçados ou renovados durante o processo, garantindo a sustentabilidade do resultado resiliente e/ou a expansão da capacidade de resiliência.

\section{RISCO, ADVERSIDADE E ESTRESSE}

A definição base da resiliência traz a questão da adaptação do indivíduo frente a situações de adversidade ou de estresse.

Adversidade é o termo associado a um estado de angústia ou sofrimento associado com o infortúnio, trauma, dificuldade, mudança, um acontecimento trágico ou com um evento positivo (Denhardt; Denhardt, 2010).

Risco, adversidade e estresse são termos mencionados frequentemente nas conceituações de resiliência. Há certa dificuldade em distingui-los, uma vez que se referem a experiências negativas. Experiências negativas de vida são inevitáveis para qualquer indivíduo, e um evento pode ser enfrentado como perigo por um indivíduo e para outro, ser apenas um desafio, o que significa dizer que a visão subjetiva de um indivíduo a determinada situação, ou seja, sua percepção, interpretação e sentido atribuído ao evento estressor é que o classificará ou não como adversidade e determinará a condição e a intensidade do estresse percebido. No que diz respeito à apreciação do que é adversidade e do estresse que ela pode causar, destaca-se a questão dos níveis de exposição e dos limites individuais de cada um (Yunes; Szymanski, 2001).

Estresse pode ser entendido como um conjunto de alterações acontecidas num organismo em resposta a um determinado estímulo que o coloque sob tensão. Diante da tensão, uma série de respostas psicofisiológicas, que tem por função atuar no evento causador de estresse e restabelecer o equilíbrio dinâmico do organismo, é gerada pelo indivíduo, o que coloca o estresse na condição de uma resposta adaptativa, pois motiva o indivíduo para a ação. Não há como prever a resposta que um indivíduo produzirá frente ao estresse. A reação ao estresse dependerá diretamente do indivíduo, do modo como este lida e significa o mundo em que vive, bem como com as variáveis do contexto (Gebert; Buengeler; Henitz, 2017).

Abordagens do estresse como processo e como estado são levantadas por Limongi-França e Rodrigues (2005, p. 32 e 33): "O stress como processo é a tensão diante de uma situação de desafio por ameaça ou conquista. O estresse como estado é o resultado positivo (eutress) ou negativo (distress) da tensão realizada pela pessoa". Essa perspectiva se coaduna com a compreensão das diferenças comportamentais das pessoas em face de situações adversas.

Uma das premissas da resiliência é que pessoas e sistemas possuem recursos ou ativos (assets) que os ajudam a sobreviver a adversidades e a lidar com o estresse causado por elas, seja por coping ou adaptação positiva. 


\section{COPING E RESILIÊNCIA}

Coping é o "[...]conjunto das estratégias utilizadas pelas pessoas para adaptarem-se a circunstâncias adversas ou estressantes" (Lyons; Pek; Wiessel, 2017, p. 9); ou seja, uma ação intencional, embasada nas "[...]constantes mudanças cognitivas e comportamentais na tentativa de administrar demandas específicas, internas elou externas, que são avaliadas pelo sujeito como excedendo ou sobrecarregando os recursos pessoais" (Lazarus; Folkman, 1984, p. 141).

Nesta perspectiva de um processo dinâmico em que o resultado é a adaptação, o enfrentamento (coping) é um conceito interrelacionado à resiliência, que pode ensejar ambiguidade conceitual, eis que não são sinônimos. (Skodol, 2010). Portanto, as estratégias podem mudar de momento para momento, durante os estágios de uma situação estressante, bem como durante os estágios de desenvolvimento do indivíduo.

A rigor, coping e resiliência são processos relacionados, condicionados a situações de adversidade / estresse; já que o primeiro é um mecanismo que gera um resultado imediato ou de curto prazo como uma resposta a um estressor, enquanto a outra requer tempo para ser desenvolvida. Enquanto o coping foca a forma, a estratégia utilizada para lidar com a situação, independentemente do resultado obtido, a resiliência concentra sua atenção no resultado da estratégia utilizada. O resultado resiliente seria a adaptação positiva, no sentido de bem-sucedida, do indivíduo frente à adversidade.

\section{ADAPTAÇÃO POSITIVA: CONFORMIDADE VERSUS SUPERAÇÃO}

As concepções de adaptação relacionadas à resiliência são variadas, como a piagetiana, na qual o indivíduo desenvolve-se graças a processos sucessivos de adaptação a situações novas. Estes processos incluem os mecanismos de assimilação e acomodação (Piaget, 1983) e que a adaptação se define pelo equilíbrio entre ambos.

Já Deslandes e Junqueira (2003) observaram duas maneiras diferentes de se conceber a resiliência no que diz respeito à adaptação. Junto com outros dois eixos que indicavam polarizações do conceito - inato versus adquirido e permanente versus circunstancial - o eixo adaptação versus superação separa conceitos que enfocam adaptação dos indivíduos, frente aos traumas e adversidades, como o desenvolvimento de comportamentos adaptados às expectativas sociais (adaptação), ou seja, definições de resiliência que têm um sentido de ajustamento passivo às normas sociais; e conceitos que enfocam o sentido de superação do trauma vivido que é elaborado simbolicamente (superação), ou seja, definições de resiliência que implicam em uma elaboração ativa dos traumas vividos, como uma maneira própria de significar as adversidades e lidar com elas.

No sentido de superação, a resiliência é um processo em que existe a recuperação da homeostase (equilíbrio), e esta recuperação pode levar a um resultado de superação do indivíduo em relação à adversidade enfrentada, quando o indivíduo aprende com a experiência adversa e se fortalece.

No que tange à adaptação, a adaptação positiva pode variar de acordo com fatores culturais e sociais, dado um determinado período de tempo, e pode não exigir a exposição a uma experiência de adversidade.

A adaptação positiva pode ser identificada no momento em que o indivíduo consegue alcançar expectativas sociais, vencendo a adversidade e desenvolvendo-se a partir dela ou quando não há sinais de desajuste do indivíduo (Melillo et al, 2004).

Neste sentido, Yunes e Szymanski referem-se à "resiliência performativa", conceito construído por Martineau (1999). Ela é definida como "[...]conformidade às normas sociais, sucesso acadêmico e empatia pelos outros, porém manifestos apenas com o objetivo de agradar ou enganar" (Yunes; Szymanski, 2001, p. 35). Manifestações de conformidade às vezes ocorrem em troca de um "preço" demasiado alto para a saúde mental de um indivíduo, que pode aparentar estar 
muito bem em relação a algo que teve que enfrentar em sua vida ou já enfrentou, mas por trás, na verdade existe uma superação que é apenas aparente.

A resiliência performativa (Yunes, 2003) refere-se ao "custo" demasiado alto para a saúde mental de um indivíduo, e seu sentido de "ajustamento social" pode produzir pessoas "adaptadas" vivendo em um silencioso desespero ou ainda pessoas adaptadas, mas "não adaptáveis", porque implica uma conformidade a certas condições e valores da sociedade, mas não implica necessariamente em saúde psicológica (Block; Kremen, 1996).

\section{DISCRIMINAÇÃO NO AMBIENTE DE TRABALHO}

Por conta de um ideal de neutralidade e tecnicismo desde a origem, as organizações adotam uma perspectiva de homogeneidade no seu cotidiano. Elas lidam com os indivíduos, que nelas trabalham, como se suas diferenças pudessem ser ocultadas sem maiores problemas, sob o manto da formalidade, dos rituais e processos organizacionais, das posições hierárquicas (Irigaray; Freitas, 2013).

$\mathrm{Na}$ realidade, de certa forma, as empresas assumem que seus empregados separam suas características e interesses pessoais dos profíssionais; ou seja, subjulgam sua dimensão de indivíduo ao "bem comum" organizacional. Esta visão é limitada, uma vez que se pode identificar a presença de racionalidades concorrentes no corpus organizacional, e que, portanto, os indivíduos não apresentam qualquer tipo de clivagem entre quem são, como homens e mulheres, dos papéis e das exigências de suas profissões.

As políticas, práticas e os discursos organizacionais, assim como o comportamento e as atitudes dos colegas de trabalho, são os fatores de maior impacto, seguidos pela legislação nacional, para que os empregados homossexuais percebam a existência de práticas discriminatórias no ambiente de trabalho (Gebert; Buengeler; Henitz, 2017).

No mundo corporativo, as políticas e práticas de diversidade, normalmente, se baseiam nos princípios da igualdade, oportunidades iguais e ação afirmativa. Em sua maioria, os discursos mobilizam-se em torno de "dignidade e respeito", associando-os à não diferenciação de empregados ou candidatos a emprego por causa de suas diferenças e ao cumprimento de legislação nacional e local com relação à não-discriminação e oportunidades iguais. No entanto, quando se trata de políticas de diversidades, as pessoas são mais propensas a aceitar as diferenças étnicas, sociais e de gênero; mas apresentam resistência à diversidade de orientações sexuais (Siqueira; Zauli-Fellows, 2006).

Mas a sexualidade é uma questão pública e organizacional, devido ao fato de ela delinear o comportamento de homens e mulheres, construir expectativas, definir posições, acesso a cargos, bem como privilégios (Saraiva; Irigaray, 2009). De fato, há evidências de que ser identificado como homossexual, no mundo corporativo, pode comprometer a ascensão profissional de um indivíduo em razão de sua dificuldade em elaborar uma rede de contatos (network), já que, muitas vezes, por constrangimento, não participará de eventos sociais da empresa (Irigaray, 2013s). Estas pressões sociais implicam algumas sensações, tais como angústia, impotência e ansiedade, uma vez que os gays se percebem obrigados a se manterem em permanente estado de vigilância pela expectativa de serem atacados física ou verbalmente a qualquer momento, introjetando, assim, atitudes sociais negativas, que podem se desdobrar em custos psicossomáticos (Ragins et al., 2003).

Por isso, não raramente, para sobreviver no ambiente corporativo, eles camuflam sua identidade sexual, esquivam-se de participar ativamente das reuniões sociais promovidas pelas empresas (Irigaray; Freitas, 2013) e se veem impingidos a controlar seus discursos, gestos e tom de voz (Foucault, 1994).

Portanto, a sobrevivência no mundo corporativo demanda adaptação, a qual pode vir na forma de camuflagem ou reserva. Desta forma, este estudo sobre a forma como os homoafetivos lidam com a identidade sexual no ambiente de trabalho revela-se pertinente. 


\section{PERCURSO METODOLÓGICO}

Nessa pesquisa, utilizamos três métodos específicos de coleta de dados: observações no campo, entrevistas e grupo de foco. Foram visitadas 23 empresas, de diferentes indústrias e tamanhos, em São Paulo ou Rio de Janeiro, nas quais um dos autores trabalhou como consultor, ministrou treinamentos ou foi convidado por algum empregado. Cada empresa foi visitada, no mínimo, quatro vezes, entre julho de 2005 e novembro de 2013. Cada visita durou, em média, seis horas e as anotações de campo foram feitas durante e posteriormente cada uma delas.

No que tange às entrevistas, mantivemos em mente as considerações de Goldenberg (2000) e optamos por um roteiro compatível com a entrevista focada, semiestruturada. $\mathrm{O}$ acesso ao campo foi facilitado por termos uma rede social muito ampla e pelas indicações de amigos (snowball). No entanto, para selecionar os participantes, consideramos as recomendações de Rubin e Rubin (1995). $\mathrm{Na}$ visão desses autores, é necessário que o pesquisador busque sujeitos que: (a) conheçam a arena cultural, situação ou experiência em estudo, (b) tenham vontade de falar e (c) tenham perspectivas diferentes.

A entrevista iniciava com a explicação ao entrevistado sobre o objeto de estudo da pesquisa. Nessa etapa, os respondentes também eram informados de que o seu anonimato seria garantido. Posteriormente, solicitamos os dados categóricos do indivíduo: idade, estado civil, idade, escolaridade, área de formação, cargo e empresa, orientação sexual declarada (e no caso de homo e bissexuais, se eram assumidos perante a família, amigos e/ou local de trabalho), local de residência, religião (se efetivamente pratica) e se possuíam um relacionamento estável (caso afirmativo, por quanto tempo). Nesse momento da coleta de dados, nossa maior preocupação foi o risco de se trabalhar com gênero e orientação sexual dicotomicamente, ou seja, perguntando aos indivíduos sobre seu gênero (homem ou mulher) e orientação sexual (hétero, homo ou bissexual); já que, sob a ótica da Queer Theory (Leap; Boellstorff, 2004) tais dicotomias são exageradamente restritivas e servem para refletir e reforçar o Weltanschauung da hegemonia masculina (Bourdieu, 2007). Dessa forma, por considerar que as variáveis "sexo", "gênero" e "orientação sexual" são dinâmicas e fluidas, só foram analisadas variáveis relevantes quando assim foram consideradas pelos respondentes.

Foram elaborados quatro roteiros de entrevistas e, no total, realizamos e, lugares reservados 67 entrevistas com homossexuais masculinos. Apenas 16 entrevistados não autorizaram a gravação da conversa e, nestas ocasiões, tomamos notas ao longo do encontro.

Em relação às entrevistas em si, os primeiros momentos foram dedicados à apresentação pessoal e da pesquisa. Quando se tratava de amigos pessoais, a conversa fluiu muito mais espontaneamente, uma vez que estes já estavam cientes do objeto de estudo e, não raramente, deixavam claro a cumplicidade existente, declarando: "eu só posso falar isso porque é para você que é meu amigo" ou ainda pelo uso de antífrases ou expressões de concordância.

No caso dos demais entrevistados indicados, procuramos ganhar sua confiança demonstrando simpatia pela sua narrativa por meio de gestos de concordância - tanto verbais quanto não-verbais. No entanto, ficou nítido que a confiança já havia sido previamente assegurada por termos sido indicados por alguém de sua confiança.

O terceiro e último método de coleta de dados foi uma manifestação espontânea desta pesquisa: o grupo de foco, o qual ocorreu no momento de saída de campo. Foi uma reunião entre oito amigos, durante um almoço informal na casa de um deles, durando, aproximadamente, sete horas. Devido ao seu grau de informalidade, não houve registro por meio de gravação e as anotações de campo só se efetuaram após o término do encontro.

Esse grupo de foco resultou ser de extrema importância para essa pesquisa, já que os participantes se sentiram mais protegidos para externarem suas experiências e seus sentimentos, alguns dos quais intencionalmente - ou não - omitidos nos encontros individuais. Esse encontro revelou também conflitos pessoais, interpessoais e divergência de pontos de vista, os quais evidenciaram fortemente a inexistência de um discurso único, validando assim, a crença pós- 
modernista da Queer Theory que ser gay é um atributo a mais, porém não é, e está longe de ser, o único a forjar a identidade social de um indivíduo e seu discurso.

No que tange ao tratamento de dados, as entrevistas, que foram gravadas, foram transcritas e submetidas à análise do discurso, pois entender a linguagem dos actantes é entender suas ações sociais (Wodak, 1999). Este agir social se caracteriza pelo fato de que toda ação é teleológica, na medida em que os atores sociais põem em ação estratégias eficazes, racionais, a fim de chegara um consenso; regulada, no sentido de que movimentos acionais dependem de normas que são estabelecidas pelo grupo de que esses atores fazem parte; intersubjetiva, na medida em que os atores sociais colocam-se em cena, oferecendo ao outro uma imagem de si, para produzir um efeito sobre eles. Neste estudo, não se entende como análise do discurso apenas uma extensão dos procedimentos distribucionais a unidades transfrásticas (Harris, 1994), etnografia da comunicação (Gumperz; Hymes, 1964), nem a análise conversacional de inspiração etnometodológica (Garfinkel, 1967); antes, como um instrumento de análise do deslocamento da história das ideias para os dispositivos enunciativos (Foucault, 2004) e para a dimensão dialógica da atividade discursiva (Bakhtin, 2003).

\section{REVELAÇÕES DO CAMPO}

A análise das falas dos nossos entrevistados, por meio da análise do discurso, possibilitounos diagnosticar duas categorias emergentes, no que tange as estratégias de sobrevivências dos gays no ambiente de trabalho e o conceito de resiliência. A primeira foi denominada "enigma no espelho" e a segunda, "respeito, aceitação e adaptabilidade".

\subsection{Enigma no espelho}

As experiências de nossos entrevistados foram permeadas de múltiplos sentimentos decorrentes de suas identidades sexuais. Houve relatos de rejeição, discriminação, agressões verbais e físicas; mas também, demonstrações de orgulho pela superação de barreiras sociais (como o reconhecimento do casamento homoafetivo, equiparacão de direitos trabalhistas com os seus pares heterossexuais) e de dificuldades pessoais (de autoaceitação). Mais do que isso, não raramente, nas entrevistas, transbordaram relatos e expressões de felicidade (risos, olhares, lágrimas e gestos), em função de nossos interlocutores terem sido aceitos e acolhidos pelos familiares, amigos e colegas de trabalho.

Todavia, conforme já sugerido em estudos anteriores (Queiroz, 2013), nossos entrevistados foram unânimes em denunciar que os homossexuais ainda são caracterizados pela sociedade, evidenciado nos seguintes fragmentos de discurso:

(01) "Grande parte da sociedade vê os gays apenas como motivo de chacota ou piada, como num grande programa humorístico. Para eles, todos os gays são bichinhas poc-poc, afeminadas, histéricas; o que é motivo de vergonha para a família".

As seleções lexicais "afeminadas" e "histéricas" desvelam que, sob o olhar heteronormativo, ser homossexual é abrir mão de pertencer ao sexo masculino, o que equipara estes sujeitos às mulheres. A rigor, como já denunciado por Irigaray (2013), o manto da homofobia encobre, na realidade, a misogenia. $O$ sequestro desta identidade de gênero resulta numa luta, por parte dos homossexuais, que sejam aceitos como homens e mulheres, que não abriram mão de suas características biológicas; apenas vivenciam sua afetividade diferentemente.

Ademais, como já sugerido por Saraiva e Irigaray (2009), o humor, principalmente na sociedade brasileira, é um instrumento de discriminação e demarcação de espaço social; isto é, aos gays é reservado o papel de bobo da corte, a quem cabe entreter a audiência com seus trejeitos ou 
objeto de piadas e anedotas. Esta realidade foi apreendida pelas seleções lexicais "motivo de chacota", "piada", "programa humorístico".

Todavia, o verdadeiro enigma no espelho jaz na dificuldade que estes indivíduos encontram em se reconhecer na forma como são descritos pela sociedade e nas manifestações culturais (Lopes, 2002). Esta angústia foi explicitada na seleção lexical "todos os gays são bichinhas poc-poc, afeminadas", a qual foi acompanhada por uma testa franzida e punhos cerrados, por parte do interlocutor. Todos os entrevistados deixaram claro que o fato de eles compartilharem os mesmos desejos sexuais não é o suficiente para que sejam caracterizados como um grupo homogêneo.

Mas, se esta adjetivação pejorativa prevalece na caracterização dos homossexuais, os quais são percebidos como um único grupo, como que estes indivíduos demarcam seus espaços na sociedade? A que custo?

Estas indagações levaram-nos a reconhecer uma segunda categoria emergente, a qual denominamos "respeito, aceitação, adaptabilidade".

\subsection{Aceitação, respeito e adaptabilidade}

As falas de todos os nossos entrevistados tiveram algo em comum: em algum momento, nossos interlocutores se refletiram sobre os desdobramentos de sua orientação sexual nas suas vidas psíquica (nomeadamente, no que se refere à autoestima), pessoal (relacionamento familiar e círculo de amizades) e, por último, profissional (carreira, ambiente de trabalho).

Esta percepção ficou evidente em fragmentos de discurso como: "[...] eu não sou gay por opção; eu nasci assim, se pudesse escolher, não seria [gay]", ou ainda, "[...]é triste não ser aceito pela família; todo mundo sabe que sou gay, mas fazem questão que eu finja ser o que não sou”, e também, "[...]para sobreviver no mundo corporativo tenho que fingir, contar historinhas, inventar namoradas; caso contrário, serei rejeitado e ridicularizado como tantos outros".

Estas falas sugerem que, sob a ótica de nossos interlocutores, grande parte da sociedade os rejeita, ou apenas os tolera; diante disso, eles se veem compelidos a lançar mão da estratégia de coping (Antoniazzi et al., 1998) a fim de alcançar um resultado resiliente, ou seja, de adaptação. Na realidade, há um esforço de pensamento, ação e comportamento para gerir ou superar situações estressantes.

Nesta pesquisa, nosso objetivo não é revisitar as estratégias de sobrevivência destes indivíduos, que foram objeto de estudo de Irigaray e Freitas (2013), mas analisar esta categoria emergente sob a ótica da resiliência, eis que tais manifestações da sociedade consubstanciam situações de adversidade ou de estresse e a definição base da resiliência - um conceito amplo que se refere a processos ou padrões de adaptação positiva e desenvolvimento, em um contexto de risco e adversidade (Luthar et al., 2000), traz a questão da adaptação do indivíduo frente às situações.

Assim, as demonstrações de rejeição, tolerância ou aceitação percebidas pelos homossexuais em relação ao contexto social consubstanciam-se em adversidade ou fatores de estresse ou fatores de risco em seu cotidiano, e os mecanismos adotados para o enfrentamento destes fatores de estresse (coping) resultam em um repertório de respostas adaptativas que variam de luta por aceitação, passando por demandas por respeito, até estratégias de enfrentamento - estratégias de sobrevivência - que podem revelar a resiliência em sua forma performativa (Martineau, 1999) ou até um resultado resiliente no sentido de superação (Carver, 1998), conforme desvelado nos seguintes fragmentos de discursos.

(02) "Os gays são vistos como fraquinhos, temperamentais, fofoqueiros [pausa] quem vai querer um funcionário com estas "competências"? [o interlocutor gesticulou as aspas]. No mundo do trabalho, a gente tem que se adaptar ao que o mercado exige. 
As seleções lexicais fraquinhos, temperamentais, fofoqueiros sugerem que nossos interlocutores têm consciência de que são qualificados, pela sociedade, por atributos que são indesejáveis no mundo corporativo. De fato, esta constatação fica evidente pelo uso do vocábulo "competências", acompanhado da gesticulação. Esta realidade demanda uma adaptação performativa, como explicitado pela seleção lexical "a gente tem que se adaptar".

Ademais, a adaptação ao que o mercado exige pressupõe a adaptação bastante e necessária que gere comportamentos que, de alguma forma, escondam conjuntos de características que possam ser rotulados como "fraquinhos", "temperamentais" ou "fofoqueiros".

Esta estratégia de sobrevivência, todavia, acarreta dor, sofrimento e estresse; o que fica evidente no seguinte fragmento de discurso:

(03) "A impressão que tenho é que nós [homossexuais] somos tolerados nas empresas, ou por conta do discurso de políticas de diversidade, ou porque fingem que não sabem quem somos; daí muita gente leva vida dupla, finge que é hétero, inventa namoradas, só para se adaptar a esse mundo corporativo hipócrita. Isso cansa [primeira sílaba bem prolongada].

A seleção lexical "somos tolerados" sugere que a pressão social manifestada na rejeição (explicitada na fala 02) implica em algumas sensações, tais como rejeição, angústia, impotência e ansiedade, consubstanciando uma adversidade - termo associado a um estado de angústia ou sofrimento associado com o infortúnio, trauma, dificuldade, mudança, um acontecimento trágico ou com um evento positivo (Avey et al., 2008) - ou fator de estresse.

O fragmento de discurso (03) também revela o mecanismo da adaptação, como estratégia de enfrentamento (coping) adotada, em resposta a uma percepção de adversidade na manifestação de tolerância, ou seja, algo imposto, mas que pode ser evitado e rejeitado quando possível, no ambiente corporativo, conforme desvela a seleção "A impressão que tenho é que nós [homossexuais] somos tolerados nas empresas, ou por conta do discurso de políticas de diversidade, ou porque fingem que não sabem quem somos".

As seleções lexicais"dai muita gente leva vida dupla, finge que é hétero, inventa namoradas", "só para se adaptar a esse mundo corporativo hipócrita" e "isso cansa" permitemnos inferir que existe um mecanismo de enfrentamento, o qual pretende um resultado de adaptação positiva, tendo como "proxys" demonstrações de conformidade com comportamentos indicativos de valores e percepções heterocêntricas: "finge que é hétero, inventa namoradas, só para se adaptar a esse mundo corporativo hipócrita".

Nesta seleção, cabe ressaltar que a adoção de comportamentos para se adaptar a um contexto social denotativamente qualificado de hipócrita desvela a manifestação de resiliência na sua forma performativa (Martineau, 1999).

Mais do que isso, também foi explicitado o estresse percebido pelo locutor na repetição de comportamentos conformes a uma parametrização heterocêntrica na fala e no prolongamento utilizado, quando profere "Isso cansa".

Todavia, para os homossexuais em questão, tolerância é muito pouco em razão do alto preço que eles pagam para se adaptar. Esta disparidade de custo-benefício fica nítida, no seguinte fragmento de discurso:

(04) "Gay só interessa quando é visto como público-alvo, que tem dinheiro para gastar, o tal do pink dollar. Por isso que nos toleram, respeito que é bom, nada (...) é como se nós estivéssemos comprando nossa carta de alforria".

O fragmento de discurso (04), à semelhança do (03), oferece seleções lexicais que nos remetem à tolerância novamente como algo imposto, mas que pode ser evitado e rejeitado quando 
possível. Neste sentido, especificamente na fala (04), o interlocutor afirma que tolerância não é suficiente; existe uma demanda por respeito.

Esta fala também revela a mercantilização da aceitação, sugerida na seleção lexical "comprando nossa carta de alforria".

Ficou evidente que estes indivíduos percebem que há diferentes ambientes, com diferentes graus de aceitacão à homafetividade e que as práticas discriminatórias fundadas em valores heterocêntricos presentes no ambiente organizacional são percebidas e avaliadas como adversidades ou fatores de estresse pelos gays, e as estratégias de sobrevivência caracterizadas por assumir a orientação sexual apenas na vida privada, ou esconder radicalmente a orientação sexual em todos os espectros da vida em sociedade (Irigaray; Paiva; Goldschmidt, 2017) revelam-se como reificações de resiliência, na medida que consubstanciam um resultado de adaptação positiva (de conformidade) à lógica heterocêntrica que permeiam tanto as políticas e práticas organizacionais como a crença na superioridade em dados modelos de relacionamento e orientação sexual.

No bojo desta discussão de uma sociedade que, por um lado aprova leis modernas que garantem a equiparação de direitos civis entre os cidadãos de todas as orientações sexuais, mas que, por outro lado, testemunha o avanço de um fundamentalismo religioso que pressiona por um retrocesso; os indivíduos homossexuais diagnosticam que, nesta arena, a saída mais pragmática é a adaptação.

Ao longo destas entrevistas, e de tantas outras, ficou evidente que se, por um lado, internamente estes indivíduos sentem a necessidade de viver uma vida plena, assumindo sua identidade sexual perante toda a sociedade, por outro, eles se sentem ameaçados por uma sociedade heteronormativa, e organizações heterocêntricas.

Reiteradamente, as experiências relatadas tinham como pano de fundo a luta por (auto)aceitação, pelo direito de exercer a homoafetividade e, acima de tudo, ser respeitado como cidadão, como ser humano. Nem sempre esta ocupação de espaço social foi fácil para os nossos interlocutores. Seu êxito variava em razão de outras dimensões: classe social, idade, religião, grau de escolaridade, estrutura familiar e, também, traços de personalidade.

Neste sentido, as estratégias de sobrevivência de assumir sua orientação sexual apenas na vida privada e de esconder radicalmente sua orientação sexual em todos os espectros de sua vida em sociedade (Irigaray, 2013) são reificações da resiliência em sua forma "performativa" (Yunes; Szymanski, 2001), eis que manifestações de conformidade ocorrem por meio da adoção de comportamentos convergentes com os papeis sociais já institucionalizados no ambiente profissional, que excluem a orientação sexual diversa da lógica heterocêntrica, bem como gestos, discursos e outros quaisquer indicadores comportamentais que revelem uma orientação sexual gay.

Cabe especial atenção àqueles que explicitam sua orientação sexual em todas as arenas sociais que atuam (Irigaray; Paiva; Goldschmidt, 2017) e podem pagar o preço: ou de não serem percebidos como adaptados ou de serem "punidos" com agressões verbais, psicológicas ou até físicas, o que consubstancia situações de risco às quais também é demandada uma resposta resiliente (Luthar et al., 2000; Zautra et al., 2010; ONG et al., 2010). Nestes casos, o resultado resiliente, sob a ótica da adaptação positiva, no sentido de superação, nos induziu a um questionamento, se há de fato uma resiliência verdadeira (no sentido de superação) demonstrada pela congruência de comportamentos que perpassam as vidas psíquica (nomeadamente, no que se refere à autoestima), pessoal (relacionamento familiar e círculo de amizades) e profissional (carreira, ambiente de trabalho), ou se é apenas performativa, com efeitos tão nocivos quanto os comportamentos indicativos de adaptação à lógica heterocêntrica, revelados nas falas anteriormente analisadas.

\section{PARA CONCLUIR}

Para Reich et al. (2010), embora a resiliência se apresente sob definições e caracterizações eivadas de certa variação, há dois temas dominantes que são centrais ao conceito de resiliência: (1) 
como uma resposta a eventos estressores/adversidades, a resiliência foca na recuperação (recovery), que é a habilidade de se recuperar do estresse, a capacidade de reaver o equilíbrio (físico e psíquico) rapidamente, retornando ao equilíbrio, ao estado saudável ou produtivo (Rutter, 1985; Irigaray; Paiva; Goldschmidt, 2017); e (2) a resiliência, como um resultado da adaptação bem-sucedida à adversidade, implica a continuidade da trajetória de recuperação, gerando sustentabilidade (sustainability) do equilíbrio saudável que permite a melhoria das capacidades funcionais para lidar com estresse/adversidade futuro, e continuar seguindo em frente diante da adversidade (Bonanno, 2004) como em um ciclo virtuoso.

Assim, as estratégias de sobrevivência adotadas pelos homossexuais, no ambiente de trabalho, podem ser interpretadas como reificação de resiliência em si, pois estes indivíduos adotam comportamentos que objetivam um resultado convergente com a "resiliência performativa"; ou seja, eles buscam agir em conformidade com as normas sociais, sucesso acadêmico e empatia pelos outros, porém manifestos apenas com o objetivo de agradar ou enganar (Yunes; Szymanski, 2001).

Estas manifestações de conformidade às vezes ocorrem em troca de um "preço" demasiado alto para a saúde mental de um indivíduo, que pode aparentar estar muito bem em relação a algo que teve que enfrentar em sua vida ou já enfrentou, mas por trás, na verdade, existe uma superação que é apenas aparente. No limite, o processo de adaptação desvela a intenção de "ajustamento social", cujo objetivo é produzir pessoas "adaptadas" vivendo em um silencioso desespero, ou ainda, pessoas adaptadas, mas "não adaptáveis" porque implica uma conformidade a certas condições e valores da sociedade, mas não implica necessariamente em saúde psicológica, o que não gera uma resposta resiliente para o minority stress (Ragins et al., 2003), que, eventualmente, limita seus desempenhos profissionais (Saraiva; Irigaray, 2009).

\section{REFERÊNCIAS}

Avey, J., Wernsing, T., Luthans, F.(2008) Can positive employees help positive organizational change? Impact of psychological capital and emotions on relevant attitudes and behaviors. The Journal of Applied Behavioral Science, 44(1), 48-70.

Bakhtin, M.(2003) Estética da criação verbal. São Paulo: Martins Fontes.

Block, J., Kremen, A.(1996) IQ and ego-resiliency: conceptual and empirical connections and separateness. Journal of Personality and Social Psychology, 70(2), 349.

Bonanno, G.(2004) Loss, trauma, and human resilience: have we underestimated the human capacity to thrive after extremely aversive events? American Psychologist, (12), 177-192.

Bourdieu, P.(2007) A dominação masculina. Rio de Janeiro: Bertrand Brasil.

Brandão, J., Mahfoud, M., Gianordoli-Nascimento, I. (2011). A construção do conceito de resiliência em psicologia: discutindo as origens. Paidéia, 21(49), 263-271.

Carneiro, R.(2015) A representação do perfil profissional demandado pelas organizações contemporâneas na perspectiva do pop-management. Rio de Janeiro: FGV.

Carver, C.S.(1998) Resilience and thriving: issues, models, and linkages. Journal of Social Issues, 54(2), 245-266.

Denhardt, J., Denhardt, R. (2010) Building organizational resilience and adaptive management. Handbook of Adult resilience, 333-349. 
Deslandes, S.F., Junqueira, M.F.P.(2003) Resiliência e maus tratos à criança. Cadernos de Saúde Pública,19(1), 227-35.

Foucault, M.(1994) An interview with Michel Foucault. In J. D. Faubion (Ed.), Power, 3, 239-297, New York: The New Press.

(2004) Ética, sexualidade, política. Rio de Janeiro: Forense Universitária.

Garfinkel, H. (1967) Studies in ethnomethodology. Englewood Cliffs, NJ: Prentice-Hall.

Gebert, D., Buergeler, C., Heinitz, K. (2017) Tolerance: a neglected dimension in diversity training? Academy Management Learning, 16 (415-438), 417-436, September.

Goldenberg, M. (2000) A arte de pesquisar: como fazer pesquisa qualitativa em ciências sociais. (4. ed.) Rio de Janeiro: Record.

Goldschmidt, C. (2015) Resiliência - um estudo exploratório da percepção de gestores sobre o constructo, nas dimensões humana e organizacional, Rio de Janeiro: FGV.

Gumperz, J., Hymes, D.(1964) The ethnography of communication. American Anthropologist, 66(6).

Harris, C.(1994) Acknowledging lesbians in the workplace: confronting the heterosexuality of organizations. Presented in Academy of Management, Dallas, TX.

Irigaray, H., Freitas, M.(2013) Estratégias de sobrevivência dos gays no ambiente de trabalho. Revista Psicologia Política, 13, 57-74.

Irigaray, H., Paiva, K., Goldschmidt, C.(2017) Resiliência organizacional: proposição de modelo integrado e agenda de pesquisa. Cadernos.Ebape.Br, 15, 390-408.

Jackson, D., Firtko, A., Edenborough, M. (2007) Personal resilience as a strategy for surviving and thriving in the face of workplace adversity: a literature review. Journal of Advanced Nursing, 60(1), $1-9$.

Kamlot, D. (2017) Resiliência organizacional e marketing social: uma avaliação de fundamentos e afinidades. Cadernos.Ebape.Br, 15, 390-408, São Paulo.

Kent, M., Davis, M.(2010) The emergence of capacity-building programs and models of resilience. Handbook of Adult Resilience, 427-449.

Lara, L., Oliveira, S.(2017) A ideologia do crescimento econômico e o discurso empresarial do desenvolvimento sustentável. Cadernos.Ebape.Br, 15(2), 326-346.

Lazarus, R., Folkman, S.(1984) Stress, appraisal, and coping. New York: Springer.

Leap, W., Boellstorff, T.(2004) Speaking in queer tongues: globalization and gay language. Chicago: University of Illinois.

Lengnick-Hall, M.L.(2011) Developing a capacity for organizational resilience through strategic human resource management. Human Resource Management Review, 21(3), 243-255. 
Limongi-França, A., Rodrigues, A.(2005) Estresse e trabalho: guia prático com abordagem psicossomática, São Paulo: Atlas.

Lopes, D.(2002) O homem que amava rapazes e outros ensaios. Rio de Janeiro: Aeroplano.

Luthar, S., Cicchetti, D., Becker, B.(2000) The construct of resilience: a critical evaluation and guidelines for future work. Child Development, (71), 543-562.

Lyons, B., Pek, S., Wiessel, J.(2017) Toward $\alpha$ "sunlit path": stigma identity management as $\alpha$ source of localized social change through interaction. Academy of Management Review, 42, 618636, October .

Martineau, S.(1999) Rewriting resilience: a critical discourse analysis of childhood resilience and the politics of teaching resilience to "kids at risk". Tese de Doutorado, UBC.

Masten, A.S., Wright, M.O.D.(2010) Resilience over the lifespan: developmental perspectives on resistance, recovery, and transformation. Handbook of adult resilience, 213-237.

Melillo, A., Soriano, R.; Méndez, J., Pinto, P.(2004) Salud comunitaria, salud mental y resiliencia. En: Melillo, A., Ojeda, E.N.S., Rodíguez, D. (org.) Resiliencia y Subjetividad. Los ciclos de la Vida, 287-300, Buenos Aires: Paidós.

Mott, L.(2006) Homofobia no Brasil. Arquipélago: Revista de Livros e Ideias, Porto Alegre: Instituto Estadual do Livro, (7), 19-21, out.

ONG, A.D., Bergeman, C.S., Chow, S.(2010) Positive emotions as a basic building block of resilience in adulthood. Hanbook of Adult Resilience, 81-93.

Piaget, J. (1983) Psicogênese dos conhecimentos e seu significado epistemológico.

Queiroz, L.G.M.(2013) Gerentes de projetos: um estudo sobre a relação entre perfis psicodemográficos, desempenho e progressão profissional, Rio de Janeiro: FGV.

Ragins, B., Cornwell, J., Miller, J.(2003) Heterosexism in the workplace - Do race and gender matter? Group \& Organization Management, (28), 45-74.

Reich, J.W., Zautra, A.J., Hall, J.S.(2010) Handbook of adult resilience, Guilford Press.

Rubin, H., Rubin I.(1995) Qualitative interviewing; the art of hearing data. California: Sage Publications.

Rutter, M.(1985) Resilience in the face of adversity: protective factors and resistance to psychiatric disorder. British Journal of Psychiatry, (147), 598-611.

(2007) Resilience, competence, and coping. Child abuse \& neglect, 31(3), 205-209.

Saraiva, L., Irigaray, H..(2009) Humor e discriminação por orientação sexual nas organizações: um estudo sobre histórias de vida. In: Encontro da Anpad - EnAnpad, (33), 19-23, 2009, São Paulo. Anais.... 
Siqueira, M., Zauli-Fellows, A.(2006) Diversidade e identidade gay nas organizações. In: Encontro de Estudos Organizacionais, 4, Porto Alegre. Anais... Porto Alegre: Anpad.

Skodol, A.(2010) The resilient personality. In Reich, J.W., Zautra, A.J., Hall, J.S. (eds.), Handbook of Adult Resilience, 112-125, New York: Guilford Press.

Tugade, M., Fredrickson, B. (2004) Resilient Individuals use emotions to bounce back from negative emotional experiences. Journal of Personality and Social Psychology, (86), 320-333.

Tusaie K., Dyer J.(2004) Resilience: a historical review of the construct. Holistic Nursing Practice, (18), 3-10.

Vieira, A., Oliveira, C.(2017) Resiliência no trabalho: uma análise comparativa entre as teorias funcionalista e crítica. Cadernos.Ebape.Br, 15, 409-427.

Wodak, R.(1999) Critical discourse analysis at the end of the 20th century. Research on Language \& Social Interaction, 32(1-2), 185-193.

Yunes, M.(2003) Psicologia positiva e resiliência: o foco no indivíduo e na família. Psicologia em Estudo, 8(1), 75-95.

, Szymanski, H.(2001) Resiliência: noção, conceitos afins e considerações críticas. Em:

Tavares, J. (org.). Resiliência e Educação, (2), 13-42, São Paulo: Cortez.

. Entrevista reflexiva \& grounded-theory: estratégias metodológicas para compreensão da resiliência em famílias. Interamerican Journal of Psychology, 39 (3), 431-438.

Zautra, A.J., Hall, J.S., Murray, K.E.(2010) A new definition of health for people and communities. Handbook of Adult Resilience, 1, 2010.

Data da submissão: 05/05/2017

Data de aceite: 05/07/2017 